\title{
TEORIA DOS LIMITES DOS LIMITES: ANÁLISE DA LIMITAÇÃO À RESTRIÇÃO DOS DIREITOS FUNDAMENTAIS NO DIREITO BRASILEIRO
} THEORY OF LIMITS LIMITS: ANALYSIS OF LIMITING THE RESTRICTION OF
FUNDAMENTAL RIGHTS IN THE BRAZILIAN LAW

\author{
${ }^{1}$ Clovis Demarchi \\ ${ }^{2}$ Fernanda Sell de Souto Goulart Fernandes
}

\section{RESUMO}

$\mathrm{O}$ artigo tem por objeto analisar a aplicação da teoria dos limites dos limites pelos Tribuna is brasileiros. Assim, especificou-se como objetivo analisar o controle das limitações e restrições ao conteúdo dos direitos fundamentais, tendo em vista elevar ao máximo os propósitos do Estado Democrático de Direito. Para alcançar tal enfoque, a pesquisa foi dividida em três momentos: no primeiro, realizou-se uma análise sobre os Direitos Fundamentais e a sua relação com o Estado e a Constituição; no segundo estudou-se a possibilidade de restrição dos Direitos Fundamentais; já no terceiro, analisou-se a limitação imposta ao legislador e ao aplicador do Direito na restrição aos Direitos Fundamentais pela teoria dos limites dos limites. Considera-se, portanto, que na atual fase do Estado Constitucional, o qual enfatiza a força normativa da Constituição e a importância dos Direitos Fundamentais, torna-se imprescindível buscar-se a efetividade dos mesmos através da concretização dos direitos constitucionalme nte reconhecidos. Neste contexto, apesar da possibilidade de relativização e restrição aos direitos fundamentais, não podem esses serem esvaziados de modo a não serem atendidos, aplicandose assim a Teoria dos Limites dos Limites. Quanto a metodologia, utilizou-se a base lógica indutiva para o desenvolvimento do trabalho.

Palavras-chave: Estado constitucional, Direitos fundamentais, Teoria dos limites dos limites

\begin{abstract}
The article focuses on analyzing the application of the theory of limits of bounds by Brazilian courts. Thus, it was specified to analyze the control of the limitations and restrictions on the contents of fundamental rights in order maximize the Democratic State of Law purposes. To achieve such an approach, the research was divided into three stages: the first, there was an analysis of the fundamental rights and their relationship with the State and the Constitution; the second studied the possibility of restriction of fundamental rights; by the third, the limitation imposed analyzed the legislator and the law of the applicator on the restriction of fundamental rights by the theory of limits of bounds. Therefore it is considered that in the current phase of the Constitutional State, which emphasizes the normative force of the Constitution and the importance of fundamental rights, it is essential to get to the same effectiveness by achieving the constitutionally recognized rights. In this context, despite the
\end{abstract}

1Doutor em Ciência Jurídica pela Universidade do Vale do Itajaí. Professor titular da Universidade do Vale do Itajaí. Universidade do Vale do Itajaí - Univali, Santa Catarina. Brasil - E-mail: demarchi@univali.br

2 Doutoranda pela Universidade do Vale do Itajaí. Professora do Curso de Direito da Universidade do Vale do Itajaí. Universidade do Vale do Itajaí - Univali, Santa Catarina. Brasil - E-mail: nanda goulart@univali.br 
possibility of relativity and restriction of fundamental rights, these not can be emptied so as not to be met by applying so the Theory of Limits Limits. The method used for the development of this study was inductive.

Keywords: Constitutional state, Fundamental rights, Theory of limits limits 


\section{INTRODUÇÃO}

O Estado Constitucional tem como uma de suas marcas justamente a força normativa da Constituição, e, assim, a importância da efetividade dos direitos que ela reconhece.

Nesse contexto, a Constituição assume especial relevância na concepção do Estado Democrático de Direito e passa a ser dotada de normatividade, vinculando, limitando e impondo a concretização dos direitos fundamentais.

Verifica-se que na prática, a fim de se alcançar um avanço ainda mais significativo é importante que se busque a concretização desses direitos constitucionalmente reconhecidos como fundamentais.

Tendo em vista que nenhum direito deve ser considerado absoluto é possível a restrição aos direitos e garantias fundamentais por meio da Constituição ou lei infraconstitucional, mas, para tanto, necessário se faz atender a todos os desdobramentos da teoria dos limites dos limites, que se materializa em obstáculos à atuação do legislador na restrição desses direitos, garantindo o efetivo exercício dos direitos fundamentais que fortalecem o Estado Democrático de Direito.(SENA, 2012).

Assim, este artigo tem por objeto analisar a aplicação da teoria dos limites dos limites pelos Tribunais brasileiros para resguardar a ação do Estado ao afetar desvantajosame nte um direito fundamental.

O Objetivo Geral é analisar o controle das limitações e restrições ao conteúdo dos direitos fundamentais, tendo em vista elevar ao máximo os propósitos do Estado Democrático de Direito. Os Objetivos Específicos são: a) analisar o conceito e a relação dos Direitos Fundamentais com a evolução do Estado e da Constituição; b) estudar a possibilidade de restrição aos Direitos Fundamentais; c) averiguar a limitação às restrições aos Direitos Fundamentais impostas ao legislador e ao aplicador do Direito.

Diante da possibilidade do controle das limitações e restrições ao conteúdo dos direitos fundamentais tem-se como problema de pesquisa a seguinte questão: A Teoria dos Limites dos Limites apresenta-se como limitação ao legislador e ao aplicador do Direito na restrição dos Direitos Fundamentais? 
A primeira hipótese seria uma negativa quanto a esta possibilidade, onde a Teoria dos Limites dos Limites não se apresentaria como limitação ao legislador e ao aplicador do Direito na restrição dos Direitos Fundamentais. E uma segunda hipótese seria afirmativa, ou seja, que a Teoria dos Limites dos Limites apresentar-se-ia sim, como limitação ao legislador e ao aplicador do Direito na restrição dos Direitos Fundamentais.

Os resultados da pesquisa poderão indicar que os direitos fundamentais são balizas para a atuação desenfreada do poder estatal e que qualquer afetação desvantajosa a estes Direitos apresenta-se como uma contradição ao caráter vinculante que as normas fundamentais naturalmente devem proporcionar. Em razão disso, observa-se que a atividade limitadora e restritiva do Estado pode ser igualmente, uma atividade limitada, resguardando tais direitos.

O artigo está dividido em três momentos: no primeiro, realiza-se uma análise sobre os Direitos Fundamentais e a sua relação com o Estado e a Constituição; no segundo estudase a possibilidade de restrição dos Direitos Fundamentais; já no terceiro analisa-se a limitação imposta ao legislador e ao aplicador do Direito na restrição aos Direitos Fundamentais através da Teoria dos limites dos limites.

Quanto à Metodologia, o relato dos resultados será composto na base lógica Indutiva com base em pesquisa bibliográfica.

\section{Direitos Fundamentais ${ }^{1}$ no Constitucionalismo Contemporâneo}

O avanço que o direito constitucional apresenta hoje é resultado, em grande parte, da afirmação dos direitos fundamentais como núcleo da proteção da dignidade da pessoa humana e da visão de que a Constituição é o local adequado para positivar as normas asseguradoras dessas pretensões. (MENDES; COELHO; BRANCO, 2009. p. 265).

\footnotetext{
${ }^{1}$ Uma das primeiras dificuldades que apresenta o tema é quanto a sua terminologia. Dessa maneira, faz -se necessário um esclarecimento sobre a terminologia mais corrente com referência ao fenômeno em questão. Diversas expressões foram utilizadas através dos tempos para designar o fenômeno dos direitos humanos, e diversas também foram suas justificações. Em nossa opinião três são expressões corretas para serem usadas atualmente: direitos humanos, direitos fundamentais e direitos do homem. Respaldamos nossa opinião no consenso geral existente na doutrina especializada no sentido de que os termos direitos humanos e direitos do homem se utilizam quando fazemos referência àqueles direitos positivados nas declarações e convenções internacionais, e o termo direitos fundamentais para aqueles direitos que aparecem positivados ou garantidos no ordenamento jurídico de um Estado.
} 
Ferrajoli propõe uma definição teórica, puramente formal ou estrutural, dos direitos fundamentais. Para ele são direitos fundamentais todos aqueles direitos subjetivos que correspondem universalmente a todos os seres humanos enquanto dotados do status de pessoa, de cidadão ou pessoas com capacidade de agir. (FERRAJOLI, 2011, p. 10).

Muito importante é a contribuição de Peces Barba para o estudo dos Direitos Fundamentais, o qual para compor seu conceito de forma mais completa destaca três aspetos principais. Inicialmente, o autor enfatiza que os Direitos Fundamentais são uma pretensão moral justificada embasada nas ideias de liberdade e de igualdade que, com o passar dos tempos, foi sendo somada a ideia de solidariedade, segurança jurídica e influencia da filosofia, política liberal, democrática e socialista. Como pretensão moral justificada deve corresponder a direitos cujo conteúdo pode ser generalizado, aplicado a todos de forma igualitária. Além disso, os Direitos Fundamentais devem ser incorporado a uma norma com poder de obrigar os destinatários e possibilidade de ser garantida. Por ultimo, os direitos fundamentais são uma realidade social, sendo influenciados pelas condições sociais, econômicas, políticas, econômicas e culturais.(PECES BARBA, 1995. p. 109).

O entendimento do conteúdo e da importância dos direitos fundamentais na atualidade requer uma abordagem da sua evolução histórica, que teve início, segundo Peces Barba no período que o autor entitula "trânsito à modernidade", representado pelo período entre a Idade Média e a Idade Moderna. (PECES BARBA, 1995. p. 145).

Contribuindo para a compreensão do tema, o autor destaca quatro linhas de evolução dos Direitos Fundamentais: positivação, generalização, internacionalização e positivação. (PECES BARBA, 1995. p. 145).

O primeiro processo de positivação compreende os direitos de liberdade ou de primeira geração e se caracteriza pela passagem da discussão filosófica ao direito positivo, uma vez que apenas quando incorporados ao direito positivo, os direitos fundamentais passam de ideias morais para a realidade.

O processo de generalização consiste na extensão do reconhecimento e proteção dos direitos de uma classe a todos os membros de uma comunidade como consequência da luta pela igualdade real, caracterizada pelos direitos sociais ou de segunda geração. 
A terceira fase, caracterizada pela internacionalização ainda está em fase inicial e compreende a tentativa de internacionalizar os direitos humanos para que eles ultrapassem fronteiras e alcancem toda a comunidade internacional.

Já na ultima fase, consistente no processo de especificação, se considera a pessoa em situação concreta para atribuir-lhe direitos específicos, decorrentes de uma condição, caracterizando a terceira geração de direitos difusos.(PECES BARBA, 1995. p. 145).

Os Direitos Fundamentais, correspondendo a interesses e expectativas de todos, formam o fundamento do próprio Estado Constitucional de Direito.

As três gerações de Estados de Direito correspondem, portanto, as três gerações de direitos fundamentais. O Estado liberal, que representa a primeira geração ou fase do Estado de Direito, é o marco em que se afirmam os direitos fundamentais de primeira geração, ou seja, as liberdades de signo individual. O Estado Social, que evidencia a segunda geração do Estado de Direito, será o âmbito jurídico-político em que se postulam os direitos econômicos, sociais e culturais. O Estado constitucional, enquanto Estado de Direito de terceira geração delimitará normativamente o meio espacial e temporal de paulatino reconhecimento dos direitos de terceira geração.”(LUNO, 2012, p. 10).

Sobre a divisão dos direitos fundamentais em gerações, alguns autores defendem que a expressão „dimensões ${ }^{\text {ee }}$ deve ser considerada mais adequada, uma vez que não haveria uma sucessão das categorias de direitos, uma substituindo a outra, mas sim, interpenetração de direitos, pois no Estado Social o que ocorre é um enriquecimento paulatino em resposta as novas exigências sociais que vão surgindo. (SIFUENTES, 2009, p. 50).

Portanto, as gerações de direito fundamentais são importantes, mas não devem ser entendidas como excludentes, mas como complementares, uma vez que o objetivo é que novos direitos sejam agregados aos já existentes.

Pisarello(2007, p. 80) relaciona o conceito e a importância dos Direitos Fundamentais com a importância da Constituição, ao prever que os Direitos Fundamentais são os interesses ou necessidades que assumem maior relevância dentro de um ordenamento jurídico determinado, sendo que uma demonstração desta relevância é a sua inclusão nas normas de maior valor dentro de um ordenamento, como são as Constituições. 
Assim, importante destacar que Direito Fundamental não é um conceito estático, imutável ou absoluto e muito pelo contrário trata-se de um fenômeno que acompanha a evolução da sociedade e das novas tecnologias, e as novas necessidades de positivação para proteger a dignidade humana, a liberdade, a igualdade e fazer da solidariedade uma realidade entre todos.(GARCIA, 2005).

Os Direitos Fundamentais assumem grande relevância no Estado Constitucional de Direito e na importância assumida pela Constituição Federal ao regulamentá-los neste tipo de Estado.

Isto porque, o Estado Constitucional se caracteriza, justamente, por ser a forma política que consagra plenamente a força normativa da Constituição e não um caráter meramente programático, sendo que as transformações ocorridas se fundamentam no relevante papel assumido pelos Direitos Fundamentais previstos em seu centro. (LUNO,2012, p. 10).

O Estado Constitucional através da força assumida pela constituição passa a transformar os valores e Direitos Fundamentais em normas jurídicas, num grau de importância e centralidade superior em relação às demais normas do sistema.

Neste contexto, a Constituição Federal de 1988 assume grande relevância em relação às constituições anteriores, uma vez que aquelas não refletiram as aspirações e necessidades mais imediatas da grande maioria da Sociedade, ao passo que a de 1988 representou um grande avanço neste sentido, principalmente por reconhecer novos direitos fruto de anseios coletivos manifestados através de lutas e conquistas sociais.

A ideia da força normativa da constituição atual supera a concepção semântica da constituição como um documento predominantemente programático e direciona para a sua imediata e direta aplicação.

O papel da constituição em um Estado Constitucional consiste num instrumento formal de materialização de direitos, fruto de conquistas de determinado momento histórico, de maneira que a carta constitucional não pode se resumir a um documento programático, mas deve estar direcionada para a imediata aplicação e efetivação dos direitos ali consagrados. 
Assim, assume importante relevância jurídica e política a ampla proteção dos Direitos Fundamentais previstos na constituição no Estado Constitucional.

Hesse enfatiza que os Direitos Fundamentais são "direitos fundamentadores de status"(HESSE, 1998, p. 230), garantindo um status jurídico constitucional ao particular, o qual compreende direitos e deveres concretos, determinados e limitados materialmente, cujo conteúdo nem para o particular, nem para os poderes estatais está disponível de forma ilimitada.

Neste contexto é importante a reflexão a respeito da restrição de Direitos, Liberdades e Garantias no ordenamento jurídico brasileiro.

\section{Restrições ${ }^{2}$ dos Direitos Fundamentais}

Para falar-se em restrição aos Direitos Fundamentais deve-se conhecer, primeiramente, o âmbito de proteção das normas constitucionais consagradoras desses direitos.

O âmbito de proteção de um direito fundamental abrange os diferentes pressupostos fáticos e jurídicos contemplados na norma jurídica e a consequência comum, a proteção fundamental. Alguns chegam a afirmar que o âmbito de proteção é aquela parcela da realidade que o constituinte houve por bem definir como objeto de proteção especial ou, se se quiser aquela fração da vida protegida por uma garantia fundamental.(MENDES; COELHO; BRANCO, 2009. p. 329).Trata-se da parcela da realidade que o constituinte houve por bem definir como objeto da proteção da garantia fundamental. É interessante, pois, fixar o bem jurídico protegido pela norma e os limites estabelecidos pelo constituinte a estes direitos fundamentais para que se tenha uma noção mais clara do âmbito de proteção. Este, em outras palavras, será fixado pela identificação dos bens jurídicos protegidos e pela amplitude desta proteção. (BESSA, 2009).

A definição do âmbito de proteção exige a análise da norma constitucional garantidora de direitos, tendo em vista: a) a identificação dos bens jurídicos protegidos e a amplitude dessa proteção; b) a verificação das possíveis restrições contempladas,

\footnotetext{
2 Neste artigo utilizar-se o termo "restrição" equivalente ao termo "limitação", os quais correspondem previsões normativas e interpretações que operam uma diminuição da esfera máxima de incidência do direito, segundo Pereira (2006 p. 138).
} 
expressamente, na Constituição e identificação das reservas legais de índole restritiva. (CANOTILHO, 2003, p. 1275).

Existe uma restrição legal de direitos fundamentais quando o âmbito de proteção de um direito fundado numa norma constitucional é direta ou indiretamente limitado através da lei. De modo geral, as leis restritivas de direitos diminuem ou limitam as possibilidades de ação garantidas pelo âmbito de proteção da norma consagradora desses direitos e a eficácia de proteção de um bem jurídico inerente a um direito fundamental. (CANOTILHO, 2003, p. 1276).

\subsection{Tipos de restrições a direitos individuais}

A compreensão da problemática das restrições de direitos, liberdades e garantias exige uma sistemática de limites, isto é, a análise dos tipos de restrições eventualmente existentes.

Para tanto se tem que as restrições podem ser:

\subsubsection{Reserva legal simples}

Podem existir restrições estabelecidas por lei quando os preceitos garantidores de direitos, liberdades e garantias admitem, de forma expressa, a possibilidade de restrições através da lei.

Vários são os dispositivos constitucionais em que o constituinte possibilitou a restrição do direito por simples reserva legal. Dentre eles pode-se destacar no artigo $5^{\circ}$ :

VI - É inviolável a liberdade de consciência e de crença, sendo assegurado o livre exercício dos cultos religiosos e garantida, na forma da lei, a proteção aos locais de culto e a suas liturgias. (sem grifo no original)

XV - É livre a locomoção no território nacional em tempo de paz, podendo qualquer pessoa, nos termos da lei, nele entrar, permanecer ou dele sair com seus bens. (sem grifo no original)

LVIII- o civilmente identificado não será submetido a identificação criminal, salvo nas hipóteses pre vistas em lei. (sem grifo no original)

Assim, diante de normas densas de significado fundamental, o constituinte defere ao legislador atribuições de significado instrumental, procedimental ou conformador/criador do direito(MENDES; COELHO; BRANCO, 2009, p.342). 


\subsubsection{Reserva legal qualificada}

Tem-se uma reserva legal qualificada quando a Constituição além de autorizar a restrição estabelece também às condições especiais, os fins a serem perseguidos ou os meios a serem utilizados.

É o que se pode verificar no inciso LX, do artigo $5^{\circ}$, da Constituição Federal ${ }^{3}$ que determina que a restrição à publicidade só se dará em respeito à defesa da intimidade ou à preservação do interesse social.

\subsubsection{Limites constitucionais não escritos ou restrições não expressamente autorizadas pela Constituição}

O seu reconhecimento é muito problemático, mas a sua admissibilidade é justificada, no contexto sistemático da constituição, em nome da garantia de outros direitos ou bens. Alguns chamam essas restrições de limites imanentes.

Esse foi o fundamento utilizado pelo Supremo Tribunal Federal ao permitir a fiscalização de correspondência de presos pela Administração penitenciária, não obstante a Constituição Federal em seu art. $5^{\circ}, \mathrm{XII}^{4}$, tenha consagrado a inviolabilidade das correspondências. Assim decidiu a Suprema Corte brasileira:

HABEAS CORPUS - ESTRUTURA FORMAL DA SENTENÇA E DO ACÓRDÃO - OBSERVANCIA - ALEGAÇÃO DE INTERCEPTAÇÃO CRIMINOSA DE CARTA MISSIVA REMETIDA POR SENTENCIADO UTILIZAÇÃO DE COPIAS XEROGRAFICAS NÃO AUTENTICADAS PRETENDIDA ANALISE DA PROVA - PEDIDO INDEFERIDO. - [...] A administração penitenciaria, com fundamento em razoes de segurança pública, de disciplina prisional ou de preservação da ordem jurídica, pode, sempre excepcionalmente, e desde que respeitada a norma inscrita no art. 41, parágrafo único, da Lei n. 7.210/84, proceder a interceptação da correspondência remetida pelos sentenciados, eis que a cláusula tutelar da inviolabilidade do sigilo epistolar não pode constituir instrumento de salvaguarda de praticas ilícitas. - O reexame da prova produzida no processo penal condenatório não tem lugar na ação sumaríssima de habeas corpus.(MELLO, 1994).

\footnotetext{
${ }^{3}$ A lei só poderá restringir a publicidade dos atos processuais quando a defesa da intimidade ou o interesse social o exigirem.

4 É inviolável o sigilo da correspondência e das comunicações telegráficas, de dados e das comunicações telefônicas, salvo, no último caso, por ordem judicial, nas hipóteses e na forma que a lei estabelecer para fins de investigação criminal ou instrução processual penal;
} 
Para Gilmar Mendes, a atividade legislativa, nessas hipóteses, estaria aparentemente facilitada pela cláusula de reserva legal subsidiária contida no art. $5^{\circ}$, II, da Constituição. Contudo, a ação limitadora - seja legislativa, judicial ou administrativa - há de ser revestida de cautela redobrada, tendo em vista a possibilidade de abusos no estabelecimento de restrições a direitos fundamentais não subordinados a reserva legal expressa.(MENDES; COELHO; BRANCO, 2009. p. 348).

\section{Limitação à restrição dos Direitos Fundamentais: a Teoria dos limites dos limites}

Da análise dos direitos individuais pode-se extrair a conclusão direta de que direitos, liberdades e garantias são passíveis de limitação ou restrição. Porém tais restrições são limitadas.

A expressão limites dos limites, que se difundiu na dogmática germânica sob a égide da Lei Fundamental de Bonn, visa a designar os diversos obstáculos normativos que restringem a possibilidade de o poder público limitar os direitos fundamentais. Tal locução originou-se de uma conhecida conferência sobre os limites dos direitos fundamentais proferida por Karl August Betterman, na sociedade jurídica de Berlim, em 1964. Segundo Betterman, as limitações aos direitos fundamentais, para serem legítimas, devem atender a um conjunto de condições formais e materiais estabelecidas na Constituição, que são os limites dos limites dos direitos fundamentais. Consoante seu pensamento, as condições mais importantes estabelecidas na Lei Fundamental são a garantia do conteúdo essencial e a dignidade humana, sendo também relevante o imperativo de que todas as limitações aos direitos fundamentais devem objetivar a promoção do bem comum. (PEREIRA, 2006, p. 298).

Surge, então, a teoria dos limites dos limites que baliza a ação do legislador quando restringe direitos individuais. Esses limites, que decorrem da própria Constituição, referem-se tanto à necessidade de proteção de um núcleo essencial do direito fundamental quanto à clareza, determinação, generalidade e proporcionalidade das restrições impostas.(MENDES; COELHO; BRANCO, 2009. p. 349).

A atividade limitadora e restritiva do Estado deve ser, igualmente, uma atividade limitada, de modo que a ação limitadora e restritiva se dê na medida estritamente necessária e indispensável à própria concretização e preservação de tais direitos e demais bens constitucionalmente protegidos. (FREITAS, 2007, p. 185). 


\subsection{O princípio da proteção do núcleo essencial}

Diante da noção do limite aos limites dos direitos fundamentais, tem-se que há o dever jurídico de proteção do núcleo essencial destes, não podendo qualquer limitação esgotar o sentido do direito fundamental na sua totalidade (GRILLO, 2015).

A compreensão do núcleo essencial como limite às leis restritivas, vale dizer, no sentido de evitar que os direitos fundamentais fiquem inteiramente à mercê do legislador, não apresenta grande dificuldade. O problema reside na formulação do conceito de núcleo essencial ou na tarefa de definir seu conteúdo (FARIAS, 2000).

Há posições dogmáticas distintas acerca da proteção do núcleo essencial. Quanto ao alcance do conteúdo essencial dos limites aos limites, a teoria relativa sustenta que o núcleo essencial deve ser verificado em cada caso, exigindo uma justificação, não podendo o conteúdo essencial ser definido de forma apriorística, mas somente após uma ponderação entre meios e fins com base no princípio da proporcionalidade. Por outro lado, na visão da teoria absoluta, os direitos fundamentais caracterizam-se como uma unidade substancial autônoma, configurando uma esfera permanente de direito fundamental que independe de qualquer situação concreta. O conteúdo essencial é um núcleo único e fixo que pode ser identificado independentemente de ponderação(GRILLO, 2015).

A ordem constitucional brasileira não contemplou qualquer disciplina direta $\mathrm{e}$ expressa sobre a proteção do núcleo essencial de direitos fundamentais. É inequívoco, porém, que o texto constitucional veda expressamente qualquer proposta de emenda tendente a abolir os direitos e garantias individuais (CF, art. 60, §4 ${ }^{\circ}$, IV). Tal cláusula reforça a ideia de um limite do limite também para o legislador ordinário.(MENDES; COELHO; BRANCO, 2009. p. 353).

Registre-se a passagem do Ministro Luiz Roberto Barroso:

Ementa: Resolução $n^{\circ}$ 23.396/2013, do Tribunal Superior Eleitoral. Instituição de controle jurisdicional genérico e prévio à instauração de inquéritos policiais. Sistema acusatório e papel institucional do Ministério Público. 1. Inexistência de inconstitucionalidade formal em Resolução do TSE que sistematiza as normas aplicáveis ao processo eleitoral. Competência normativa fundada no art. 23, IX, do Código Eleitoral, e no art.

105, da Lei $n^{\circ}$ 9.504/97. 2. A Constituição de 1988 fez uma opção inequívoca pelo sistema penal acusatório. Disso decorre uma separação rígida entre, de um lado, as tarefas de investigar e acusar e, de outro, a função propriamente jurisdicional. Além de preservar a imparcialidade do 
Judiciário, essa separação promove a paridade de armas entre acusação e defesa, em harmonia com os princípios da isonomia e do devido processo legal. Precedentes. 3. Parâmetrode avaliação jurisdicional dos atos normativos editados pelo TSE: ainda que o legislador disponha de alguma margem de conformação do conteúdo concreto do princípio acusatório - e, nessa atuação, possa instituir temperamentos pontuais à versãopura do sistema, sobretudo em contextos específicos como o processo eleitoral - essa mesma prerrogativa não é atribuída ao TSE, no exercício de sua competência normativa atípica. 4. Forte plausibilidade na alegação de inconstitucionalidade do art. $8^{\circ}$.da Resolucão n $23.396 / 2013$. Ao condicionarainstauracão de inquérito policial eleitoral a uma autorização do Poder Judiciário, a Resolucão questionada institui modalidade de controle judicial prévio sobre a conducão das investigacões, em aparente violacão ao núcleo essencial do princípio acusatório.[...]. (BARROSO, 2014).

\subsection{O princípio da proporcionalidade}

Sempre que houver limitação às normas jusfundamentais o princípio da proporcionalidade deve ser observado, de maneira que nos atos do Poder Público sempre haja correspondência entre os fins visados e os meios empregados.(GRILLO, 2015)

O princípio da proporcionalidade vem sendo utilizado na jurisprudência do Supremo

Tribunal Federal como instrumento para solução de colisão entre direitos fundamentais.

EMENTA: DNA: submissão compulsória ao fornecimento de sangue para a pesquisa do DNA: estado da questão no direito comparado: precedente do STF que libera do constrangimento o réu em ação de investigação de paternidade (HC 71.373) e o dissenso dos votos vencidos: deferimento, não obstante, do HC na espécie, em que se cuida de situacão atípica na qual se pretende - de resto, apenas para obter prova de reforco - submeter ao exame o pai presumido.emprocessoque temporobjeto apretensão de terceiro de verse declarado o pai biológico da crianca nascida na constância do casamento do paciente: hipótese na qual, à luz do princípio da proporcionalidade ou da_razoabilidade. se impõe evitar a afronta à dignidade pessoal que, nas circunstâncias, a sua participacão na perícia substantivaria. (sem grifo no original).(PERTENCE, 1998).

A concepção da teoria dos limites dos limites possui ligação com o caráter de princípio dos direitos fundamentais, isto é, os princípios, como mandados de otimização, podem ser cumpridos em diferentes graus, em virtude de sua condição prima facie. (SCHAEFER, 2001, p.77).

E é em virtude de os princípios serem mandados de otimização e não mandados definitivos, que os conflitos entre regras jurídicas serão resolvidos no âmbito da validade, ou seja, a regra válida exclui a outra, o conflito de princípios será resolvido levando em conta seu 
peso. Assim, para a solução de conflito de direitos fundamentais, imprescindível é a aplicação da ponderação ou balanceamento dos direitos conflitantes, levando-se em conta as características especiais do caso concreto. (KRETZ, 2005, p.82).

\subsection{Restrição Genérica e Abstrata}

A teoria dos limites dos limites impõe, ainda, que a restrição deve ser abstrata. Nestes termos, a lei que venha a limitar o direito fundamental não pode ser casuística, discriminatória, sob pena de ofensa aos princípios da igualdade material e da segurança jurídica. Do mesmo modo, a interpretação das normas que venham dispor de restrições a esse direito deve ser feita de forma a evitar contradições com a Constituição. A ingerência no âmbito dos direitos fundamentais a pessoas determinadas, atingindo-as individual e concretamente afronta os postulados básicos do Estado Democrático de Direito, que veda o tratamento desigual e arbitrário no sentido de prejudicar ou beneficiar tais pessoas. (SENA, 2012).

Não há dúvida da inadmissibilidade da adoção de leis singulares, individuais ou pessoais com o objetivo de restringir direitos. Segundo Canotilho (2003, p. 614), lei individual restritiva inconstitucional é toda lei que:

- imponha restrições aos direitos, liberdades e garantias de uma pessoa ou de várias pessoas determinadas;

- imponha restrições a uma pessoa ou a um círculo de pessoas que, embora não determinadas, podem ser determináveis por intermédio da conformação intrínseca da lei e tendo em conta o momento de sua entrada em vigor.

Assim, o critério fundamental para a identificação de uma lei individual restritiva não é a sua formulação ou o seu enunciado linguístico, mas o seu conteúdo e respectivos efeitos. Daí reconhecer a possibilidade de leis individuais camufladas, isto é, leis que, formalmente, contêm uma normação geral e abstrata, mas que, materialmente, segundo o conteúdo e efeitos, dirigem-se a um círculo determinado ou determinável de pessoas. (CANOTILHO, 2003, p. 614).

\section{CONSIDERAÇÕES FINAIS}

O estudo teve como objetivo analisar o controle das limitações e restrições ao conteúdo dos direitos fundamentais, tendo em vista elevar ao máximo os propósitos do Estado Democrático de Direito. 
Para a melhor compreensão do tema foram feitas considerações preliminares a respeito da sistemática dos direitos fundamentais, bem como da possível restrição de tais direitos, finalizando com o estudo da Teoria dos Limites dos Limites.

O papel da constituição em um Estado Constitucional consiste num instrumento formal de materialização de direitos, fruto de conquistas de determinado momento histórico, de maneira que a carta constitucional não pode se resumir a um documento programático, mas deve estar direcionada para a imediata aplicação e efetivação dos direitos ali consagrados.

Assim, assume importante relevância jurídica e política a ampla proteção dos Direitos Fundamentais previstos na constituição no Estado Constitucional.

Como os direitos fundamentais são balizas para a atuação desenfreada do poder estatal, qualquer afetação desvantajosa aos mesmos apresenta-se como uma contradição ao caráter vinculante que as normas fundamentais naturalmente devem proporcionar. Em razão disso, sustenta-se que a atividade limitadora e restritiva do Estado deve ser, igualmente, uma atividade limitada, resguardando tais direitos.

Assim, descarta-se a primeira hipótese da pesquisa e se confirma a segunda em que a Teoria dos Limites dos Limites apresenta-se como limitação ao legislador e ao aplicador do Direito na restrição aos Direitos Fundamentais, pois, como afirma, a expressão "limites dos limites", visa a designar os diversos obstáculos normativos que restringem a possibilidade de o poder público limitar os direitos fundamentais. Por isso, sabe-se que existem limites a todos os direitos, mas, torna-se necessário confirmar até onde se pode limitá-los, visto que o que se quer evitar é o possível desvirtuamento dos direitos.

\section{REFERÊNCIAS DAS FONTES CITADAS}

BESSA, Leandro Sousa. Colisões de direitos fundamentais: propostas de solução. Disponível em: http//www.conpedi.org.br/manaus/arquivos/anais/XIVCongresso/125.pdf. Acesso em 22 de julho de 2015.

CANOTILHO, José Joaquim Gomes. Direito Constitucional e Teoria da Constituição.7 ed. 8 reimp.Coimbra: Almedina, 2003. 
FARIAS, Edilsom. Restrição de direitos fundamentais. Seqüência: Estudos Jurídicos e Políticos, Florianópolis, p. 67-82, jan. 2000. ISSN 2177-7055. Disponível em: <https://periodicos.ufsc.br/index.php/sequencia/article/view/15416>. Acesso em: 05 ago. 2015. doi:http://dx.doi.org/10.5007/15416.

FERRAJOLI, Luigi. Por uma Teoria dos Direitos e dos Bens Fundamentais. Tradução de Alexandre Salim, Alfredo Copetti Neto, Daniela Cademartori, Hermes Zaneti Júnior, Sérgio Cademartori. Porto Alegre:Livraria do Advogado, 2011.

FREITAS, Luiz Fernando Calil de. Direitos fundamentais: limites e restrições. Porto Alegre: Livraria o Advogado, 2007.

GARCIA, Marcos Leite.O processo de formação do ideal dos Direitos Fundamentais: algunsaspectos destacados da gênese do conceito. Disponível em http://www.conpedi.org.br/manaus/arquivos/anais/XIVCongresso/052.pdf, acesso em10/07/2014.

GRILLO, Fernanda Fontenelle. Os limites aos limites dos direitos fundamentais à luz da Constituição da República Federativa do Brasil de 1988. Disponível em: http://fernandafgrillo.jusbrasil.com.br/artigos/157601138/os-limites-aos-limites-dos-direitosfundamentais-a-luz-da-constituicao-da-republica-federativa-do-brasil-de-1988. Acesso em 22 de julho de 2015.

HESSE, Konrad. Elementos de Direito Constitucional da República Federal da Alemanha. Trad. Luiz Afonso Heck. Porto Alegre: Sérgio Fabris, 1998.

KRETZ, Andrietta. Autonomia da vontade e eficácia horizontal dos direitos fundamentais. Florianópolis: Momento Atual. 2005.

LUNO, Antonio Henrique Pérez. Perspectivas e Tendências Atuais do Estado Constitucional. Tradução de José Luis Bolzan de Morais e Valéria Ribas do Nascimento. Porto Alegre: Livraria do Advogado, 2012.

MENDES, Gilmar Ferreira. COELHO, InocencioMartires. BRANCO, Paulo Gustavo Gonet. Curso de Direito Constitucional. São Paulo: Saraiva. 2009.

PASOLD, Cesar Luiz. Metodologia da Pesquisa Jurídica: Teoria e Prática. 12 ed. rev. São Paulo: Conceito Editorial, 2011

PECES BARBA, Gregório. Curso de DerechosFundamentales: Teoria General. Madrid: Universidad Carlos III de Madrid. 1995.

PEREIRA, Jane Reis Gonçalves. Interpretação Constitucional e Direitos Fundamenta is : uma contribuição ao estudo das restrições aos direitos fundamentais na perspectiva da teoria dos princípios. Rio de Janeiro: Renovar, 2006.

PISARELLO, Gerardo. Los derechossociales y sus garantias. Elementos para uns reconstrución. 2007.

SENA, Renata Martins. Direitos e Garantias Fundamentais e a Teoria dos Limites dos Limites. Dísponível em: http//blog.newtonpaiva.br/direito/wp-content/uploads/2012/08/PDFD13-06.pdf. Acesso em 22 de julho de 2015. 
SIFUENTES, Mônica. Direito fundamental à educação: a aplicabilidade dos dispositivos constitucionais. Porto Alegre: Núria Fabris, 2009.

SCHAEFER, Jairo Gilberto. Direitos Fundamentais: Proteção e Restrições. Porto Alegre: Livraria dos Advogados. 2001. 